\title{
PEDAGOGIA DA ALTERNÂNCIA NAS ESCOLAS DO CAMPO NO QUILOMBO KALUNGA DO MIMOSO: DESAFIOS E POSSIBILIDADES
}

\author{
Maria Santana Nunes Alves ${ }^{1}$ \\ Ana Roseli Paes dos Santos ${ }^{2}$
}

\section{INTRODUÇÃO}

As escolas do campo, na maior parte do Brasil, seguem um regime de frequência igual às escolas do meio urbano. Entretanto, existem muitas diferenças entre esses contextos, obrigando-nos a repensar se esse regime é o mais adequado à realidade do aluno campesino e das escolas do campo. Dessa forma, no princípio dessa discussão deve estar à relação do homem com sua terra, os saberes historicamente produzidos pelas pessoas que vivem do e no campo, buscando integrar o conhecimento da vida com o conhecimento escolar. Nesse contexto, uma proposta educativa que vem sendo amplamente desenvolvida é a formação pelo sistema de alternância. Essa proposta visa integrar os diferentes tempos e espaços formativos ao conjunto de experiências e saberes dos sujeitos envolvidos no processo educativo (SILVA, 2010). A produção teórica no âmbito da Educação do Campo revela que a Pedagogia da Alternância tem se constituído eixo fundamental das experiências educativas nos projetos, programas e políticas públicas para 0 ensino nas escolas da zona rural (SILVA, 2010; MOLINA, 2009; MENEZES, 2002). Há que se evidenciar que no Estado do Tocantins estão sendo realizadas, em diferentes níveis de ensino, experiências educativas de formação por alternâncias, a saber: Escolas Famílias Agrícolas; Escolas Quilombolas e Curso de Licenciatura em Educação do Campo-UFT.

É nesse contexto de desenvolvimento que situamos o objeto de estudo desta pesquisa: a experiência do ensino por alternância implantada em três escolas

\footnotetext{
${ }^{1}$ Aluna do Curso de Licenciatura em Educação do Campo com habilitação em Artes Visuais e Música na Universidade Federal do Tocantins. E-mail: <santana_nunes@yahoo.com.br>

${ }^{2}$ Professora Assistente do Curso de Licenciatura em Educação do Campo com habilitação em Artes Visuais e Música na Universidade Federal do Tocantins. E-mail: <anaroseli@mail.uft.edu.br>
} 
do campo na região Quilombola Kalunga do Mimoso no município de Arraias (TO), em parceria com a Secretaria Municipal de Educação de Arraias (SEMED/Arraias) e a Universidade Federal do Tocantins (UFT).

\title{
PEDAGOGIA DA ALTERNÂNCIA
}

A Pedagogia da Alternância surge na primeira metade do século $X X$, como uma alternativa pedagógica para atender aos interesses educacionais dos jovens, filhos de camponeses franceses. Posteriormente, esta proposta pedagógica foi disseminada em outros países, sendo, na atualidade, desenvolvida por coletivos diversos, em diferentes modalidades de educação, conforme os textos celebram:

\begin{abstract}
Um pequeno grupo de agricultores franceses insatisfeitos com o sistema educacional de seu país, o qual não atendia, a seu ver, as especificidades de uma Educação para o meio rural, iniciou em 1935, um movimento que culminou no surgimento da Pedagogia da Alternância (GIMONET, 1999; ESTEVAM, 2003; MAGALHÃES, 2001). Esse grupo enfatizava a necessidade de uma educação escolar que atendesse às particularidades psicossociais dos adolescentes e que também propiciasse, além da profissionalização em atividades agrícolas, elementos para 0 desenvolvimento social e econômico da sua região (UNEFAB, 2007).
\end{abstract}

A introdução da Pedagogia da Alternância no Brasil ocorreu no final da década de 1960, mediada pelo modelo italiano de Programa de Alternância (Maison Familiali Italiana de Castel franco-Vêneto). Dessa forma, surgem as Escolas de Famílias Agrícolas (EFA), em 1969, no Estado do Espírito Santo. No entanto, as experiências francesas, denominadas no Brasil como Casas Familiares Rurais (CFR), só foram implantadas em nossa sociedade na década de 1980. Queiroz (2004) destaca que, com estas duas experiências, isto é, EFA e CFR, que se constituíram referências, foram criados em âmbito nacional, em 2004, os Centros Familiares de Formação por Alternância (CEFFA), integrando as diversas experiências de Pedagogia da Alternância em nossa sociedade.

$O$ conceito de alternância vem sendo definido, entre muitos autores, como um processo contínuo de aprendizagem e de formação na descontinuidade de atividades e na sucessão integrada de espaços e tempos (QUEIROZ, 2004; BEGNAMI, 2004; SILVA, 2000; GIMONET, 1999). 
A formação por alternância tanto inclui quanto transcende o espaço escolar e, portanto, a experiência torna-se um lugar com estatuto de aprendizagem e produção de saberes em que o educando assume o papel de ator protagonista, apropriando-se individual e coletivamente do seu processo de formação. Assim, a Pedagogia da Alternância passa a ser entendida como uma metodologia que favorece $o$ acesso e a permanência dos jovens e adultos do campo nos processos escolares, antes dificultada por sua característica seriada e estanque, sem articulação com a realidade e os modos da vida rural (BRASIL, 2006).

Recentemente, em nossa sociedade, o movimento nacional da Educação do Campo vem adotando a Pedagogia da Alternância em suas propostas educativas, seja em projetos, programas e em políticas públicas, coordenadas pelo Ministério do Desenvolvimento Agrário (MDA), a exemplo da experiência e materialidade do Programa Nacional de Educação na Reforma Agrária (PRONERA) e dos cursos de Licenciatura em Educação do Campo sob a gestão do Ministério da Educação (MEC). De acordo com Silva (2010), a ampliação e consolidação dessas experiências e o reconhecimento do potencial educativo de suas propostas, sobretudo no âmbito do Movimento da Educação do Campo, contribuíram para disseminação e utilização da estratégia pedagógica da alternância para além da rede dos CEFFA.

Na perspectiva da Educação do Campo, as fases denominadas tempoescola e tempo-comunidade não podem ser compreendidos de forma separada, embora haja distinção no que diz respeito a espaço, tempo, processos e produtos. Os diferentes tempos e espaços de aprendizagens estão intrinsecamente ligados à forma de morar, trabalhar e viver no campo e anunciam outra forma de fazer a escola, de avaliar, de relação com os conteúdos, das ferramentas de aprendizagem, da relação entre quem ensina e quem aprende.

Segundo Caldart, a alternância é uma das pedagogias produzidas em experiências de escola do campo visando integrar a escola com a família e a comunidade do educando. A Educação do Campo tem "permitido a troca de conhecimentos e o fortalecimento dos laços familiares e do vínculo dos educandos com o assentamento ou acampamento, com o movimento e a terra" (2004, p.104). Para essa autora, pensar o ensino por alternância implica considerar dois momentos distintos (CALDART, 2004, p.105): 
O tempo-escola, onde os educandos têm aulas teóricas e práticas, participam de inúmeros aprendizados, se auto-organizam para realizar tarefas que garantam o funcionamento da escola, avaliam o processo e participam do planejamento das atividades, vivenciam e aprofundam valores;

O tempo-comunidade é o momento onde os educandos realizam atividades de pesquisa da sua realidade, de registro desta experiência, de práticas que permitem a troca de conhecimento nos vários aspectos.

Como método, a proposta da Pedagogia da Alternância objetiva atender aos interesses do coletivo, seguindo dias alternados com as seguintes organizações: alternavam-se tempos em que os jovens permaneciam na escola - que naquele primeiro momento consistia em espaço cedido pela própria paróquia - com tempos em que estes ficavam na propriedade familiar. No tempo-escola, o ensino era coordenado por um técnico agrícola; no tempo-família, os pais se responsabilizavam pelo acompanhamento das atividades dos filhos. A ideia básica era conciliar os estudos com o trabalho na propriedade rural da família (NOGUEIRA, 1999; GIMONET, 1999; ESTEVAM, 2003; BEGNAMI, 2004).

\section{A EXPERIÊNCIA DA ALTERNÂNCIA NAS ESCOLAS DO CAMPO NO MUNICÍPIO DE ARRAIAS (TO)}

O município de Arraias, localizado no sudoeste do Estado do Tocantins, tem quatorze escolas no campo e duas escolas no perímetro urbano, que recebem crianças e jovens de várias comunidades do campo. Entre os anos 2013 e 2014 foi proposta uma experiência de alternância na educação básica em três dessas escolas. Essa experiência foi idealizada e implantada pela Secretaria Municipal de Educação de Arraias (SEMED/Arraias). No entanto, seis meses depois, a experiência foi abandonada, em função de um conjunto de avaliações negativas feitas, tanto pela SEMED quanto por alguns segmentos da sociedade, tais como o Conselho Municipal de Educação de Arraias, pelos pais que a princípio não acreditavam que seria possível aprender a partir de uma nova estratégia de ensino, pelo gestor municipal por achar que essa prática gerava despesa aos cofres públicos, pela sociedade de forma geral por não conhecer a Pedagogia da Alternância, e daí a descrença num primeiro momento. 
As três escolas do campo em funcionamento situam-se na região do Quilombo Kalunga do Mimoso, sendo uma no Povoado Mimoso outra na região da Fazenda Aparecida que, atualmente, está recebendo os alunos da região das Matas, onde estava localizada a Escola das Matas, e uma escola-polo construída recentemente, para onde foram transferidos muitos alunos, a Escola Aparecida Eveny de Paula e Souza.

A extensa dimensão territorial do meio rural do município de Arraias tem gerado muitas dificuldades para a viabilização de políticas públicas. Dificuldades estas agravadas pela divisão das terras após a certificação das comunidades quilombolas. A comunidade Quilombola Kalunga do Mimoso, por exemplo, está situada a $120 \mathrm{~km}$ da cidade, servida apenas por estrada de terra.

As escolas do município que estão localizadas no campo, comumente, apresentam uma estrutura de duas salas de aula, uma cozinha e um banheiro no sistema de fossa. O nível de escolaridade ofertado nas escolas pesquisadas vai do pré-escolar ao $7 .^{\circ}$ ano do ensino fundamental, com média de 30 a 40 estudantes por escola, apenas duas merendeiras e três professores (embora haja uma rotatividade por falta de permanência dos docentes), alguns com formação em pedagogia, outros, em matemática e alguns sem qualquer habilitação ou formação incompleta. Esses profissionais da educação trabalham em regime de contrato, o que não garante estabilidade no emprego, havendo, consequentemente, grande rotatividade de profissionais nas escolas.

Com relação ao que concebe a SEMED acerca da Pedagogia da Alternância, os dados revelam que essa pedagogia, no contexto das escolas e da SEMED, caiu como uma grande novidade. Assim, a SEMED afirma que, por ser um método novo no contexto da secretaria, não encontrou subsídios em termos teóricopráticos sobre a alternância que pudessem dar suporte à experiência. Buscou orientações nas Diretrizes Operacionais para a Educação Básica das Escolas do Campo, na LDB ก.ำ 9394/96, Resoluções e Decretos, além de pesquisar experiências desenvolvidas em outras instituições.

A justificativa da SEMED para a implantação da modalidade de alternância nas três escolas do campo do município foi pautada em elementos estruturais ligados diretamente ao acesso e permanência dos alunos na escola. Vale ressaltar que parte dos alunos saía de suas casas entre 3h e $4 \mathrm{~h}$ da manhã, para estar na escola às $7 \mathrm{~h} 30$ para o turno matutino, e às $13 \mathrm{~h} 00$ para o período 
vespertino, porque havia disponível apenas um transporte para percorrer um trajeto superior a $300 \mathrm{~km}$, entre as residências dos alunos e suas respectivas escolas.

Essa dinâmica adotada pelo transporte escolar traz graves consequências: a negação aos direitos da criança e do adolescente de ter escola perto de casa; o baixo rendimento escolar; a evasão escolar; a distância entre a residência dos alunos e a escola (os alunos chegam a ficar em média seis horas dentro do ônibus escolar entre os deslocamentos). Esses obstáculos levaram a SEMED a propor uma mudança no sistema de ensino: do regular para o integral ou para o regime de alternância, ou seja, algumas escolas de outras regiões passaram a funcionar em regime integral e outras em regime de alternância. Considerando as dificuldades enfrentadas pelas escolas do campo, a SEMED aprovou a proposta de implantação do ensino em regime de alternância como experiência.

Para viabilizar a implantação dessa experiência educativa, a secretária, com muito esforço, junto à Secretaria Municipal de Transporte, conseguiu dois ônibus escolares e alterou também o sistema da merenda. No regime "normal", os alunos tinham uma refeição por dia. $\mathrm{Na}$ experiência do regime por alternância, as escolas passaram a oferecer quatro refeições ao dia. Neste período, ocorreu um significativo aumento do número de alunos nessas escolas. O grande contingente de alunos matriculados, em função da experiência do ensino por alternância, constituiuse em fator importante para que o Conselho Municipal de Educação e os próprios docentes superassem, inicialmente, a rejeição a essa modalidade de ensino, por considerarem que os alunos não cumpririam a carga horária de 800 horas e 200 dias letivos, conforme estabelecido pela legislação educacional.

A proposta pedagógica de alternância, elaborada pela Secretaria de Educação, em 2013, e implementada logo após nas Escolas Municipais do Campo (Eveny de Paula e Souza, Nossa Senhora da Conceição e Matas), consistiu em um processo educativo em que se alternam períodos de aprendizagem em tempocomunidade com períodos de tempo-escola. Por meio de instrumentos pedagógicos (plano de estudo, caderno da realidade, caderno de acompanhamento, visita à família e avaliação contínua) promoveu-se uma articulação entre a comunidade e a ação pedagógica escolar.

Nessa perspectiva, o tempo-escola caracterizou-se por possibilitar a inserção do aluno na escola em tempo integral, e o tempo-comunidade, etapa da formação do educando desenvolvida no meio sociofamiliar, com as orientações e 
acompanhamento de um professor itinerante acompanha os processos pedagógicos, potencializando, assim, o desenvolvimento para o próximo tempo-escola (SEMED/Arraias, 2014).

Os dados coletados revelam que tanto as atividades do tempocomunidade quanto às do tempo-escola foram devidamente planejadas e adequadas à realidade, à pesquisa, aos trabalhos práticos, à avaliação, ao acompanhamento docente e ao envolvimento dos diferentes segmentos que constituem a comunidade escolar; e que, na sua execução, foram acompanhadas pelos educadores responsáveis pela turma. O tempo-comunidade foi realizado após as atividades intensivas, ou seja, duas semanas de tempo-escola e uma semana de tempo-comunidade, com acompanhamento pedagógico, execução de projetos, pesquisas escolares sobre a realidade local, proporcionando a construção do conhecimento, a partir de atividades práticas de ensino e pesquisa nas comunidades (SEMED/Arraias, 2014).

Com a implementação do ensino por alternância, alterou-se a oferta da educação básica nas três escolas analisadas. Elas passaram a atender até o sétimo ano, com expectativa de ampliar gradativamente a oferta, ou seja, até o ensino médio. Dentro dessa nova proposta educativa, a SEMED apostava na inclusão, na diversidade, na permanência, em situações nas quais os alunos estariam mais envolvidos com o processo educativo.

A nova proposta pedagógica foi elaborada para atender às escolas por um período de seis meses, em caráter de experiência, sendo acordado com os pais dos educandos o retorno ao sistema regular, caso a experiência não obtivesse êxito. Durante os três primeiros meses da experiência, a SEMED conseguiu um número elevado de alunos que retornaram e frequentavam regularmente a escola. Os pais estavam satisfeitos com a aprendizagem dos filhos, pois eles também estavam aprendendo com os projetos desenvolvidos no tempo-comunidade e contribuindo nos processos de aprendizagem o qual envolvia toda a família. Todos estavam envolvidos nas tarefas de cultivo, na criação de animais, em ideias novas para a lavoura entre outros projetos e espaços de aprendizagem.

Porém, após seis meses da experiência do ensino por alternância, ocorreu à substituição da Secretária de Educação, o que provocou a interrupção da experiência, sendo em seguida abandonada pela SEMED. A nova secretária alegou em relatório que "as despesas são exorbitantes para o município, além disso, as 
estruturas físicas não são adequadas para tal atendimento" (SEMED/Arraias, 2014, p.3). As "despesas exorbitantes" da qual trata o documento era o aumento de mais um transporte escolar e de suprimentos para preparo das merendas. Em nenhum momento do relatório foi feita menção ao fato do retorno e permanência dos alunos nas escolas, do envolvimento salutar da família no processo de aprendizagem, do meio de origem, das pessoas do convívio dos alunos que contribuíram com seus saberes de vida para enriquecer o saber institucionalizado.

\section{METODOLOGIA}

Do ponto de vista da abordagem do problema, o presente estudo inserese na pesquisa qualitativa apresentando algumas características descritas por Bogdan e Biklen (1994): a) o ambiente natural como fonte direta; b) o caráter descritivo da investigação qualitativa; c) maior interesse pelo processo do que simplesmente pelos resultados; d) a análise dos dados de forma indutiva. Portanto, nesta abordagem é possível coletar dados ricos em pormenores descritivos sobre a implementação e desenvolvimento da pedagogia da alternância nas escolas do campo do Município de Arrais no Estado do Tocantins. Do ponto de vista dos procedimentos técnicos, a pesquisa conduz à realização de um estudo documental resultando em um relatório descritivo com a pretensão de retratar a realidade de forma completa através de uma coleta detalhada e aprofundada de dados, já que investiga a implantação da pedagogia da alternância na Escola Municipal Eveny de Paula e Souza, Escola Municipal Nossa Senhora da Conceição e Escola da Mata. Os procedimentos metodológicos seguiram as etapas: a) contato com os gestores escolares, para solicitar a autorização para desenvolver o estudo nas escolas e estabelecer uma parceria com a UFT; b) estudo e análise documental; c) entrada no terreno para observações; d) solicitação de colaboração e preparação de entrevistas semiestruturadas direcionadas aos pais, aos professores e aos representantes da Secretaria de Educação do Município de Arraias (TO); d) transcrição dos dados das entrevistas e das observações no terreno; e) redação do relatório do estudo.

\section{RESULTADOS E DISCUSSÃO}


A partir do ano de 2014 as Escolas Municipais Eveny de Paula e Souza, Nossa Senhora da Conceição e da Mata adotaram o regime de alternância. $O$ tempo-escola e o tempo-comunidade foram interligando meios e instrumentos pedagógicos específicos, capazes de construir uma harmonia entre os saberes da comunidade e a ação pedagógica. No tempo-escola o aluno estudava em tempo integral. As atividades do tempo-escola eram devidamente planejadas e adequadas à realidade da comunidade escolar e de origem dos alunos. Eram consideradas as práticas e as vivências dos educandos de acordo com as suas necessidades e disponibilidade, o que chamamos de experiências práticas planejadas no espaçoescola. No tempo-comunidade um professor itinerante se deslocava até o meio social dos alunos para desenvolver atividades pedagógicas extracurriculares, projetos planejados no tempo-escola e fazer o acompanhamento dos conteúdos pedagógicos que serviriam de base para o processo pedagógico do próximo período de tempo-escola. Eram realizadas atividades intensivas de pesquisas sobre a realidade local, em cada uma das disciplinas, levando em consideração a indissociabilidade entre teoria e prática. A maioria das disciplinas tiveram períodos destinados à aplicabilidade, verificabilidade e construção do conhecimento, a partir de atividades práticas.

De acordo com o estudo foi possível observar que existe não apenas a possibilidade de o regime de alternância ser adotado, como também a urgência dessa adoção, uma vez que o número de evasão havia sido reduzido e as crianças puderam programar junto com os professores os momentos pedagógicos com base nas atividades agrárias, culturais e sociais do seu meio de origem. As vantagens observadas desta proposta foram: a) redução da evasão escolar; b) possibilidade de a comunidade escolar conhecer sua ascendência a partir da configuração inicial do grupo; c) reconhecimento por parte dos coordenadores da necessidade de outro regime de frequência diferenciado para as escolas do campo d) evidenciou a necessidade de mobilização efetiva da SEMED para a melhoria do ensino no campo; e) demonstrou ser imperativo o apoio da gestora das escolas no período 2013-2014, que apostou nessa proposta para erradicar parte dos problemas da comunidade escolar; f) a permanência e retorno de muitos alunos que estavam fora da escola; g) a inclusão escolar.

A principal desvantagem que o estudo demonstrou foi a falta de continuidade do projeto nos anos seguintes, porque parte dos novos gestores 
alegam que as estruturas não eram viáveis e as despesas eram exorbitantes para os cofres públicos. De fato, os gastos aumentaram, mas o ganho com a inclusão e a oportunidade de todas as crianças e jovens do campo de participar da escola supera a visão capitalista da SEMED. Há meios de reduzir os gastos com a alimentação com projetos escolares de hortas comunitárias, com a compra de produtos de agricultores familiares, para além de uma série de situações que poderiam ser implementadas para reduzir tais custos, o que em hipótese alguma tira a responsabiliza do Município, do Estado, da Federação do dever de subsidiar a educação para todos como reza a Constituição e demais leis que regulam o sistema educativo.

\section{CONCLUSÃO}

De fato, a população estudantil rural necessita, urgentemente, de políticas públicas que levem em conta as diferenças entre as escolas do campo e as escolas da zona urbana. As necessidades do homem do campo são bastante diferentes, a começar pela sua relação com a terra, com a sua cultura, com a manutenção da sua subsistência, com seus saberes. Sendo assim, é possível concluir que um pouco mais de investimento e o conhecimento aprofundado das Diretrizes Operacionais da Educação do Campo são fundamentais para a melhoria, tanto da educação em geral quanto da implantação de futuras proposta pedagógicas, que tenham como escopo o direito à educação para todos, como uma ação estratégica para a emancipação e cidadania de todos os sujeitos que vivem no campo.

\section{REFERÊNCIAS}

BEGNAMI, João Batista. Uma geografia da pedagogia da alternância no Brasil: Brasília: Cidade, 2004. (Unefab Documento Pedagógico).

BOGDAN, Robert C.; BIKLEN, Sari K. Investigação qualitativa em educação. Porto: Porto, 1994.

BRASIL. Parecer 01/2006 do CNE/CEB, que reconhece a Pedagogia da Alternância. Brasília: CNE/CEB, 2006.

CALDART, Roseli S. Pedagogia do movimento Sem Terra. São Paulo: Expressão Popular, 2004. 
ESTEVAM, Dimas O. Casa Familiar Rural: a formação com base na Pedagogia da Alternância. Florianópolis: Insular, 2003.

GIMONET, Jean-Claude. Nascimento e desenvolvimento de um movimento educativo: as Casas Familiares Rurais de Educação e Orientação. I Seminário Internacional da Pedagogia da Alternância. Anais... Salvador, 03 a 05 nov. 1999.

MAGALHÃES, Reginaldo S. A nova economia do desenvolvimento local. Cadernos CUT, São Paulo, n.ำ 17, 2001.

MENEZES, Raquel R. Pedagogia da Alternância e Novo Paradigma Educativo: Estudo Comparativo entre os Quatro Pilares do Movimento EFA'S e os Saberes Necessários à Educação do Futuro. Portugal, Universidade Nova de Lisboa, dez. 2002.

MOLINA, Mônica C. et al. Educação do Campo e formação profissional: a experiência do Programa Residência Agrária, Brasília: MDA, 2009.

NOGUEIRA, J. D. Casa Familiar Rural no Paraná: organização e implementação de um programa. Dissertação (Mestrado). UFV, Viçosa, MG, 1999.

QUEIROZ, João Batista de. Construção das Escolas Famílias Agrícolas no Brasil: ensino médio e educação profissional. 2004. Tese (Doutorado em Educação), Universidade de Brasília (UnB), Brasília (DF), 2004.

SILVA, Lourdes H. da. Concepções \& Práticas de Alternâncias na Educação do Campo: Dilemas e Perspectivas. Revista Nuances: estudos sobre Educação. Ano XVII, v. 17, n.ำ18, p.180-192, jan./dez. 2010.

SILVA, Lourdes $H$. da. A relação escola-família no universo das experiências brasileiras de formação em alternância. Tese (Doutorado), Pontifícia Universidade Católica, São Paulo. 2000.

TOCANTINS. ARRAIAS. Secretaria Municipal de Educação de Arraias. Memorial: Ensino por Alternância nas Escolas do Campo. Arraias, 2014.

TOCANTINS. ARRAIAS. Secretaria Municipal de Educação de Arraias. Proposta do Ensino por Alternância nas Escolas do Campo. Arraias, 2013.

UNEFAB. Revista da Formação por Alternância. Brasília: União Nacional das Escolas Famílias Agrícolas do Brasil. n. 4. jul. 2007.

Notas

\footnotetext{
'Em 12 de setembro de 2005 a Fundação Cultural Palmares certificou a Comunidade Kalunga do Mimoso como comunidade quilombola, e no dia 16 de dezembro de 2010 o Governo Federal decretou a criação do Território do Kalunga do Mimoso com 57.465ha.

ii acompanhamento pedagógico do Professor itinerante seguiu a seguinte estruturação: os alunos foram organizados em grupos de acordo com a localização geográfica de sua comunidade e o docente se deslocava para essas localidades, em datas e locais previamente acertados para desenvolvimento das atividades planejadas.
} 